\section{(6) OPEN ACCESS}

\title{
Long-term excess mortality of patients with treated and untreated unruptured intracranial aneurysms
}

\author{
Liisa Pyysalo, ${ }^{1}$ Tapio Luostarinen, ${ }^{2}$ Leo Keski-Nisula, ${ }^{3}$ Juha Öhman ${ }^{1}$
}

\begin{abstract}
${ }^{1}$ Department of Neurosurgery, Tampere University Hospital, Tampere, Finland

${ }^{2}$ Finnish Cancer Registry, Helsinki, Finland

${ }^{3}$ Department of Radiology, Tampere University Hospital, Imaging Centre, Tampere, Finland
\end{abstract}

\section{Correspondence to} Liisa Pyysalo, Department of Neurosurgery, Tampere University Hospital, PO Box 2000, Tampere FIN-33521, Finland; liisa.pyysalo@uta.fi

Received 27 April 2012 Revised 16 January 2013 Accepted 22 January 2013 Published Online First 19 February 2013

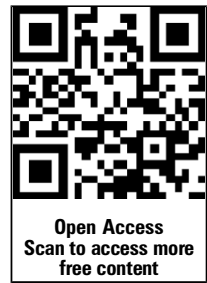

To cite: Pyysalo L, Luostarinen T, KeskiNisula L, et al. J Neurol Neurosurg Psychiatry 2013;84:888-892.

\begin{abstract}
Background and aim Subarachnoid haemorrhage (SAH) patients have an excess mortality proportion in long-term outcome studies because of the high rate of cerebrovascular and cardiovascular deaths. The aim of the present study was to assess the excess long-term mortality among patients with unruptured aneurysms with no previous SAH and to compare excess mortality after coiling, clipping and without treatment.

Methods Between 1989 and 1999, a total of 1294 patients with intracranial aneurysms were admitted to our hospital. Of these, 1154 had previous SAH and were excluded leaving 140 patients with 178 intracranial unruptured aneurysms as the study population. The patients were followed up until death or by the end of April 2011. Causes of death were determined. Relative survival ratios (RSRs) were calculated and compared with the matched general population.

Results Mean follow-up time was 13 years (range 1-19). During the follow-up period, 36\% of patients died. Death was caused by cerebrovascular event in half of the cases. There were $12 \%$ excess mortality at 15 years in men and $35 \%$ excess mortality in women compared with general population. Excess mortality among women over 50 years was significantly higher than that among men ( $p=0.018)$.

Conclusions Patients with untreated unruptured aneurysms have $50 \%$ excess long-term mortality compared with general population. Men with treated unruptured aneurysms have a survival proportion comparable with matched general population. Women, instead, have $28 \%$ excess mortality after surgical treatment and $23 \%$ excess mortality after endovascular treatment of unruptured aneurysms.
\end{abstract}

\section{INTRODUCTION}

Mortality after aneurysmal subarachnoid haemorrhage (SAH) remains high in spite of the treatment methods developed. Overall case fatality rates have been shown to be between $33 \%$ and $77 \%$ at 1 year after bleeding, with only slightly decreased in-hospital mortality from 1986 to $2001 .^{1-12}$ Even patients with successfully treated ruptured aneurysms and good outcome 1 year after bleeding have an excess death rate in long-term outcome studies. ${ }^{13-15}$ General cerebrovascular and cardiovascular causes of death are higher among SAH patients than among general population. ${ }^{12} 13 \quad 15$ However, long-term mortality in patients with unruptured aneurysms is not well studied in spite of the increasing number of incidentally discovered and aggressively treated aneurysms. The management of unruptured aneurysms is controversial because the risk of treatment is thought to be greater than the risk of rupture. ${ }^{16}$ Thus, our aim was to assess excess long-term mortality among patients with unruptured aneurysms.

\section{METHODS}

Patients

Our hospital serves as a primary and secondary care centre for patients with intracranial aneurysms, with a catchment area of approximately 1.2 million inhabitants. Between 1989 and 1999, a total of 1294 patients with intracranial aneurysms were admitted to our hospital. Of these, 1154 had previous SAH and were excluded leaving 140 patients with 178 intracranial unruptured aneurysms as the study population. All patients were followed up until death or by the end of April 2011, and no patients were lost from the follow-up. A total of 50 out of the 140 patients $(36 \%)$ died, and death certificates were obtained from Statistics Finland. The study was approved by the Hospital Ethics Committee and Statistics Finland.

\section{Statistical analysis}

Excess mortality of the patients was measured by one minus relative survival ratio (RSR). The RSR is the ratio of the observed survival proportion divided by the expected survival proportion of a comparable group of Finnish general population matched for sex, age and calendar time. The expected survival proportions were estimated by Ederer II method. ${ }^{17}$ Applying this method, follow-up year-specific expected survival proportion is estimated as the average of the annual patient-specific expected survival proportions of the patients alive at the start of the follow-up year. The cumulative expected survival proportion is estimated as the product of the follow-up yearspecific expected survival proportions. In this study, the survival probability of Finnish general population of same sex, age and calendar time as the patient served as annual patient-specific expected survival proportion and changed each consecutive year of patient's follow-up. Relative survival measured the survival experience of patients corrected for mortality from competing risks of death. However, if the patients have, for example, more severe comorbidities than the group of general population for comparison, the excess mortality is not due to only disease of interest, and relative survival underestimates survival related to the disease of interest only. RSRs and 95\% CIs were estimated by survival package SURV3 V.3.01 (Finnish Cancer Registry, Helsinki, Finland). Differences in relative 
Table 1 Patient demographics with the actual number in each group except mean age and aneurysm size

\begin{tabular}{|c|c|c|c|c|c|c|c|c|c|}
\hline & \multicolumn{4}{|l|}{ Men } & \multicolumn{4}{|l|}{ Women } & \multirow[b]{2}{*}{$\mathbf{p}$} \\
\hline & No treatment & Embolisation & Surgery & Total & No treatment & Embolisation & Surgery & Total & \\
\hline $\mathrm{N}$ & 25 & 22 & 18 & 65 & 21 & 34 & 20 & 75 & \\
\hline Mean age at diagnosis (years) & 57.4 & 49.0 & 49.6 & 52.1 & 64.1 & 52.5 & 50.0 & 54.6 & 0.1 \\
\hline Hypertension & 13 & 7 & 8 & 28 & 11 & 10 & 11 & 32 & 1.0 \\
\hline Diabetes & 1 & 1 & 1 & 3 & 1 & 2 & 1 & 4 & 1.0 \\
\hline Hypercholesterolaemia & 2 & 1 & 2 & 5 & 1 & 1 & 2 & 4 & 0.7 \\
\hline Previous stroke & 8 & 4 & 4 & 16 & 8 & 7 & 4 & 19 & 1.0 \\
\hline Other cardiovascular disease & 3 & 0 & 2 & 5 & 4 & 7 & 1 & 12 & \\
\hline Anticoagulant therapy & 4 & 2 & 1 & 7 & 5 & 4 & 3 & 12 & 0.5 \\
\hline Aneurysm with neurological (mass) symptom & 6 & 3 & 3 & 12 & 7 & 8 & 5 & 20 & 0.3 \\
\hline Anterior circulation aneurysm location & 19 & 23 & 19 & 61 & 13 & 32 & 23 & 68 & \\
\hline Vertebrobasilar aneurysm location & 4 & 0 & 0 & 4 & 6 & 1 & 0 & 7 & \\
\hline Mean fundus size (mm) & 15.5 & 8.2 & 10.3 & 11.4 & 13.2 & 10.7 & 12.5 & 11.9 & 1.0 \\
\hline Multiple aneurysms & 4 & 5 & 3 & 12 & 6 & 7 & 7 & 20 & 0.3 \\
\hline Death at follow-up & 16 & 6 & 4 & 26 & 12 & 6 & 6 & 24 & \\
\hline Neurological death & 8 & 2 & 1 & 11 & 9 & 2 & 2 & 13 & \\
\hline SAH & 4 & 1 & 0 & 5 & 3 & 2 & 1 & 6 & \\
\hline Other cerebrovascular than SAH & 4 & 1 & 1 & 6 & 6 & 0 & 1 & 7 & \\
\hline Cardiovascular & 3 & 1 & 0 & 4 & 2 & 2 & 3 & 7 & \\
\hline Cancer & 3 & 0 & 1 & 4 & 1 & 1 & 0 & 2 & \\
\hline Other & 2 & 3 & 2 & 7 & 0 & 1 & 1 & 2 & \\
\hline
\end{tabular}

survival between patient groups were tested applying likelihood ratio tests. ${ }^{18}$

\section{RESULTS}

Patients (65 men and 75 women) were aged $18-86$ years (mean 54) at the time of diagnosis of the unruptured intracranial aneurysm (table 1). A total of $15(11 \%)$ out of 140 patients were scrutinised because of familial history of SAH and 32 patients $(23 \%)$ had neurological symptoms because of an unruptured aneurysm. Rest, 66\%, were incidental findings.

A total of 66 out of 178 aneurysms were left untreated. Sixty-four aneurysms were treated with endovascular coiling and 48 aneurysms were treated surgically. A total of 50 out of 140 patients (36\%) died during the 1702 patient-year follow-up period. Eleven patients ( $8 \%$ ) died from aneurysmal bleeding and 13 died due to cerebrovascular disease other than SAH. Cause of death in one patient was unverified stroke. Nine out of 11 patients who died due to SAH had large aneurysms $(>15 \mathrm{~mm}$, mean $24 \mathrm{~mm}$ ) and 6 aneurysms were symptomatic. Aneurysm fundus size was larger in the dead than in the survival group (mean

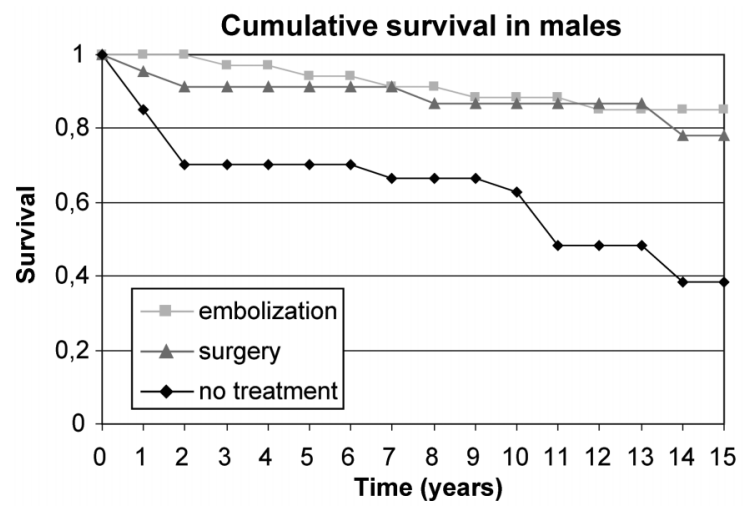

$14 \mathrm{~mm}$ and $10 \mathrm{~mm}$, respectively, $\mathrm{p}=0.02$ ). Patients with multiple aneurysms had no excess mortality compared with patients with only one aneurysm. Eleven patients died of cardiovascular diseases (22\% of deaths), 6 of malignancies (12\% of deaths) and 8 of other causes (16\% of deaths). Patients with treated aneurysms were less likely to die from neurologically related causes than patients with untreated aneurysms (32\% vs $61 \%$ of deaths). Cumulative observed survival proportions are shown in figure 1.

The 5-year cumulative RSR was 0.78 among men and 0.56 among women with untreated unruptured aneurysms, implying $22 \%$ and $44 \%$ excess mortality, respectively (table 2). The 10 -year cumulative RSR was 0.80 in men and 0.49 in women in untreated aneurysms. The 15 -year cumulative RSR was 0.50 among women and men with untreated unruptured aneurysms, implying 50\% excess mortality (figure 2).

Mortality among treated groups did not differ from general population at 5 -year follow-up period. Women had 19\% excess mortality in the embolisation group and $8 \%$ excess mortality in the surgical group at 10 -year follow-up. Such difference was not found in men. At 15-year follow-up, men with embolised

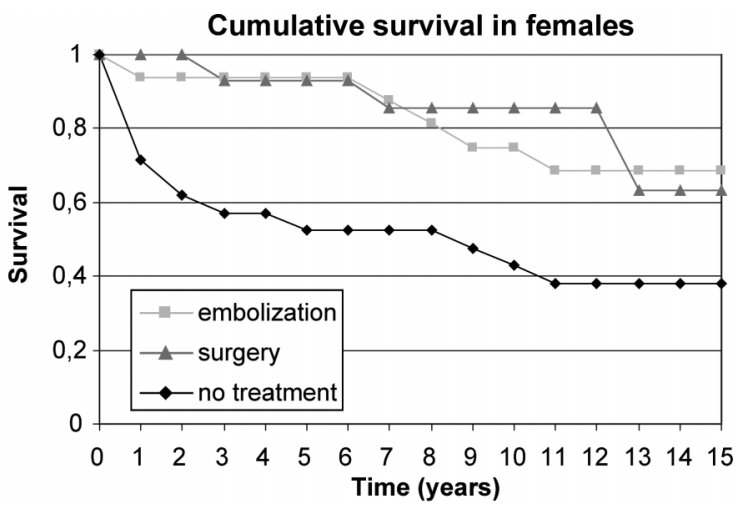

Figure 1 Cumulative observed survival proportions in men and women. 
Table 2 Cumulative relative survival ratio (RSR) in different treatment groups

\begin{tabular}{|c|c|c|c|c|}
\hline & At 1 year & At 5 years & At 10 years & at 15 years \\
\hline \multicolumn{5}{|l|}{ No treatment } \\
\hline \multicolumn{5}{|l|}{ Men (31) } \\
\hline Alive & 27 & 19 & 18 & 4 \\
\hline Cumulative RSR & 0.87072 & 0.77865 & 0.79619 & 0.53259 \\
\hline $95 \% \mathrm{Cl}$ & 0.690 to 0.962 & 0.570 to 0.931 & 0.559 to 0.992 & 0.276 to 0.846 \\
\hline \multicolumn{5}{|l|}{ Women (27) } \\
\hline Alive & 21 & 12 & 10 & 3 \\
\hline Cumulative RSR & 0.72735 & 0.56173 & 0.49419 & 0.47843 \\
\hline $95 \% \mathrm{Cl}$ & 0.510 to 0.878 & 0.347 to 0.768 & 0.282 to 0.732 & 0.261 to 0.743 \\
\hline \multicolumn{5}{|l|}{ Embolisation } \\
\hline \multicolumn{5}{|l|}{ Men (34) } \\
\hline Alive & 34 & 33 & 30 & 15 \\
\hline Cumulative RSR & 1.00988 & 0.99549 & 1.00257 & 1.06370 \\
\hline $95 \% \mathrm{Cl}$ & 0.000 to 0.000 & 0.856 to 1.040 & 0.834 to 1.083 & 0.870 to 1.168 \\
\hline \multicolumn{5}{|l|}{ Women (17) } \\
\hline Alive & 16 & 15 & 12 & 10 \\
\hline Cumulative RSR & 0.94297 & 0.97004 & 0.81039 & 0.76765 \\
\hline $95 \% \mathrm{Cl}$ & 0.721 to 0.995 & 0.742 to 1.023 & 0.546 to 0.971 & 0.496 to 0.958 \\
\hline \multicolumn{5}{|l|}{ Surgery } \\
\hline \multicolumn{5}{|l|}{ Men (24) } \\
\hline Alive & 23 & 21 & 20 & 8 \\
\hline Cumulative RSR & 0.96374 & 0.94982 & 0.95419 & 0.92089 \\
\hline $95 \% \mathrm{Cl}$ & 0.796 to 1.000 & 0.762 to 1.015 & 0.745 to 1.048 & 0.631 to 1.080 \\
\hline \multicolumn{5}{|l|}{ Women (14) } \\
\hline Alive & 14 & 13 & 12 & 8 \\
\hline Cumulative RSR & 1.00547 & 0.95945 & 0.92754 & 0.72207 \\
\hline $95 \% \mathrm{Cl}$ & 0.000 to 0.000 & 0.708 to 1.020 & 0.650 to 1.039 & 0.428 to 0.949 \\
\hline
\end{tabular}

aneurysms had no excess mortality compared with the matched Finnish male population (figure 3), and men with clipped aneurysms had approximately $8 \%$ excess mortality (figure 4). However, women had excess mortality in all subgroups (figure 1). The 15 -year cumulative RSR was 0.77 in the embolisation group and 0.72 in the surgical group, implying $23 \%$ and $28 \%$ excess mortality, respectively (figures 3 and 4). Excess mortality was related to age and was, after 50 years of age, higher among women than among men. Both genders under 50 years had 15-year cumulative RSR around 0.90 , but the 15 -year cumulative RSR in patients over 50 years was 0.91 in men and 0.49 in women $(p=0.018)$.

Males, no treatment

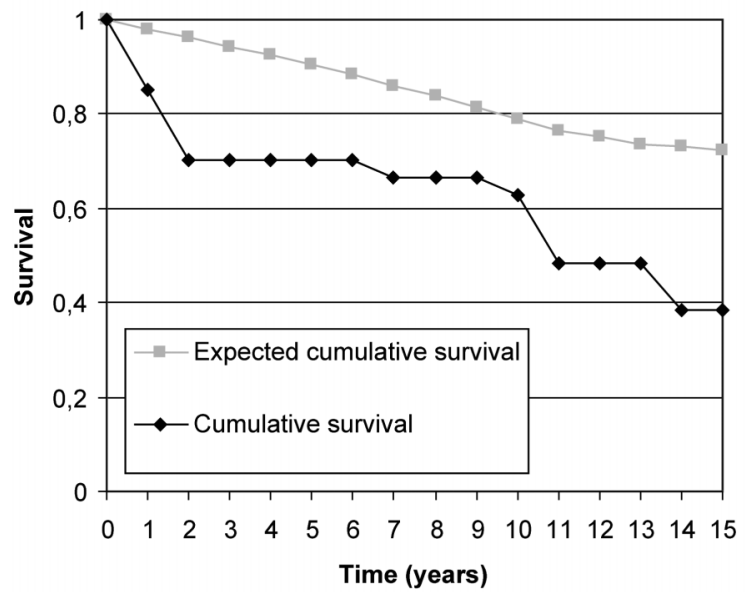

\section{DISCUSSION}

SAH patients have an excess mortality proportion in long-term outcome studies because of the high rate of cerebrovascular and cardiovascular deaths. ${ }^{12-15}$ To the best of our knowledge, there are no studies comparing long-term mortality of patients with clipped, coiled and untreated unruptured aneurysms compared with the general population. In previous outcome studies of patients with unruptured aneurysms, patients have had a previous SAH and thus outcome can be related to previous $\mathrm{SAH}$, not truly to unruptured aneurysms. ${ }^{19} 20$ Long-term survival among patients with unruptured aneurysms has been studied in only one large, administrative database study. ${ }^{21}$ In that study, it was stated that survival among

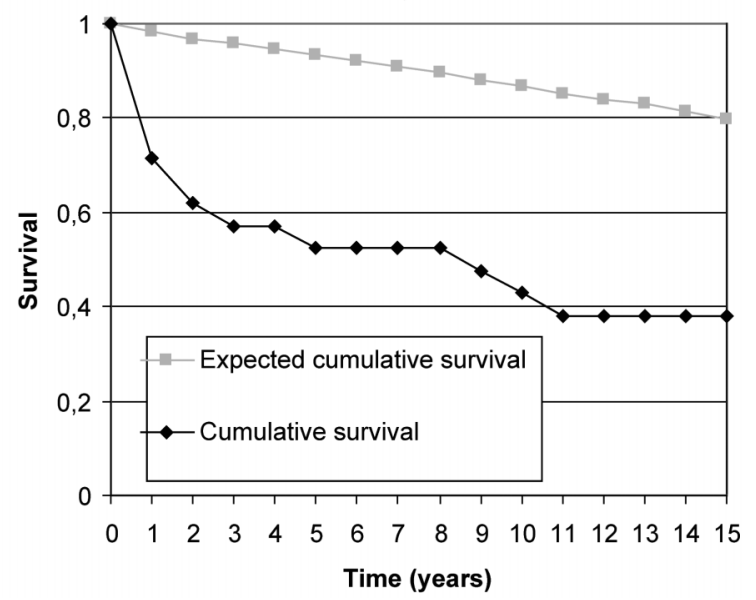

Figure 2 Cumulative observed and expected survival proportions in men and women with no treatment. 

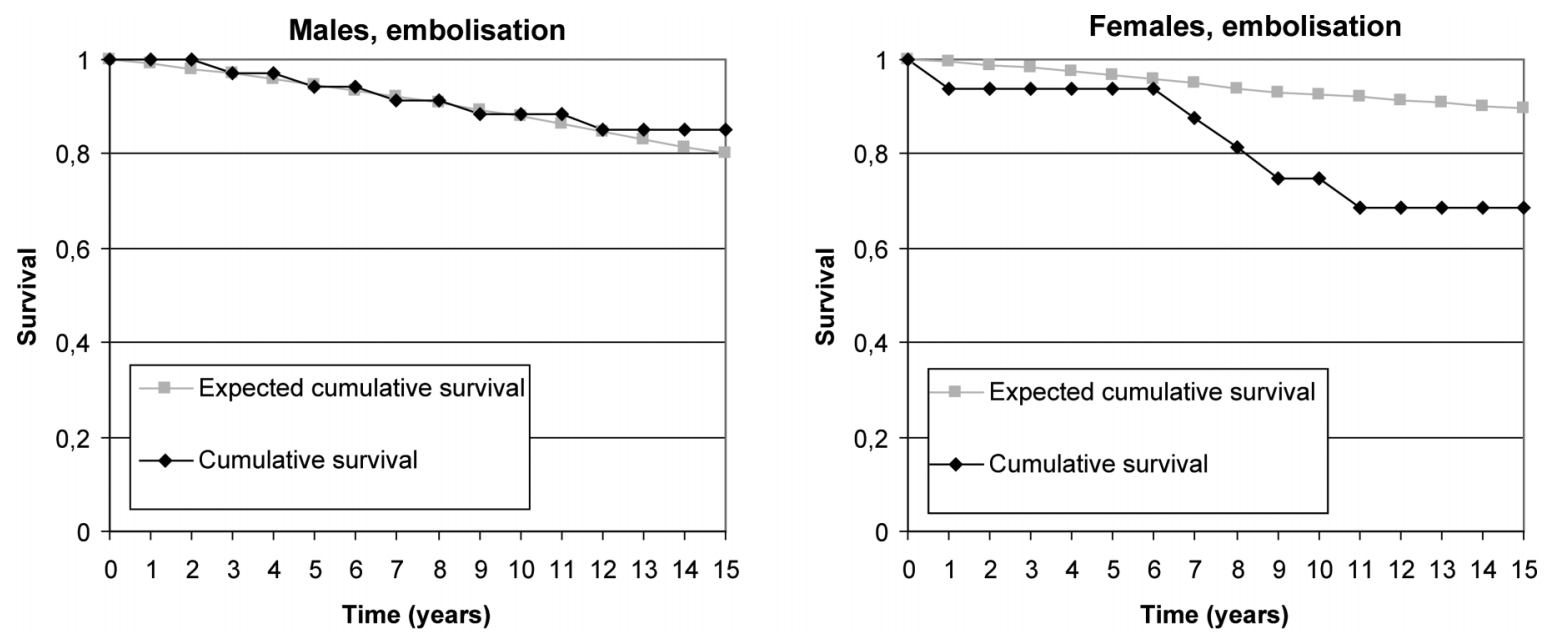

Figure 3 Cumulative observed and expected survival proportions in men and women after embolisation.

SAH patients was significantly lower than that among patients with unruptured aneurysms, but after the first-year post-clipping, differences in the survival rate diminished. ${ }^{21}$

Britz et $a l^{21}$ found that patients with untreated unruptured aneurysms were $30 \%$ more likely to die than patients in the clipped group. Our study corroborates this and we found that patients with untreated unruptured aneurysms had long-term excess mortality compared with population matched for age, sex and calendar time. However, in both studies, demographical features differed between groups: patients with untreated aneurysms were older, more likely to be men and had more comorbidities. Thus, higher mortality among untreated and treated may be attributable to bias. However, Britz et $a l^{21}$ found that survival differed between the surgically treated group and the untreated group also after controlling for age and comorbidities using proportional hazards modelling. The question of confounding by indication is difficult to assess in our retrospective study. Smoking and other risk factors related to lifestyle are not reliably assessed in this retrospective study, and such risk factors may be associated to premature death. Thus, it is not clear that the aneurysm itself is the problem; rather the aneurysm is simply a marker of predisposition towards vascular and, in particular, cerebrovascular disease. The excess mortality should probably be lower and relative survival higher in this study, if smoking and other comorbidities were taken account

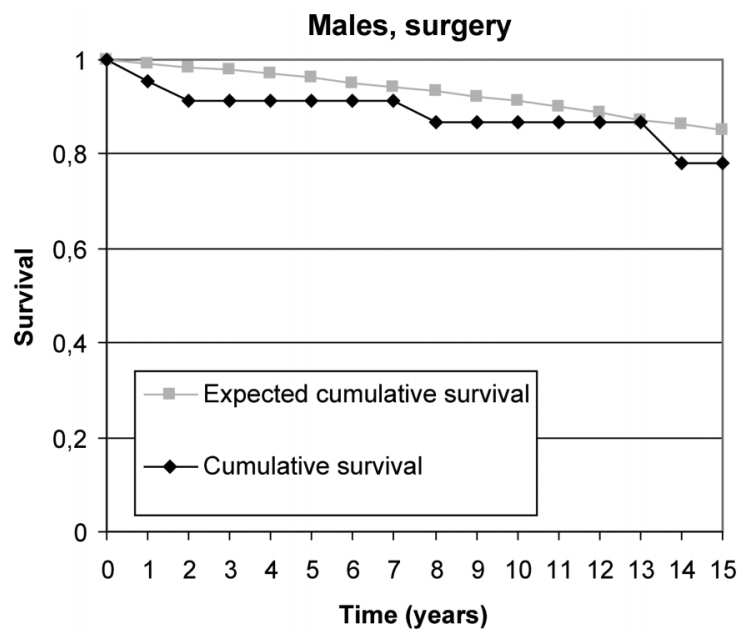

of. This limitation might alter the study conclusion to be that smoking people are more likely to die from cardiovascular disease than people who do not smoke. However, smoking in previous years in Finland has been more common among men, so the difference between female and male survival can unlikely be explained only by smoking.

Indication for treatment or no treatment was not clear and about 150 out of 380 unruptured aneurysms were left untreated in our hospital between 1989 and 1999. Patients over 60 years were usually not treated, likewise patients with numerous comorbidities and non-independent status. Posterior circulation aneurysms were not as often treated as anterior circulation aneurysms. Decisions were made individually and are difficult to assess retrospectively. Most aneurysms in 1990s were detected because of previous $\mathrm{SAH}$, and excluding those patients, the study population is quite small. Nowadays, unruptured aneurysms are more often detected because of common use of MRI and CT. Unfortunately, there might be bias as we could analyse only patients admitted to the hospital because of the aneurysms, not whole prevalence of population with unruptured aneurysms.

Our study is the first study to scrutinise all death certificates of patients with unruptured aneurysms. The validity of Finnish death certificates is assessed to be appropriate. ${ }^{22}$ By law, the death certificate has to include a short case history relevant to medical certification of death. More than $90 \%$ of Finnish death

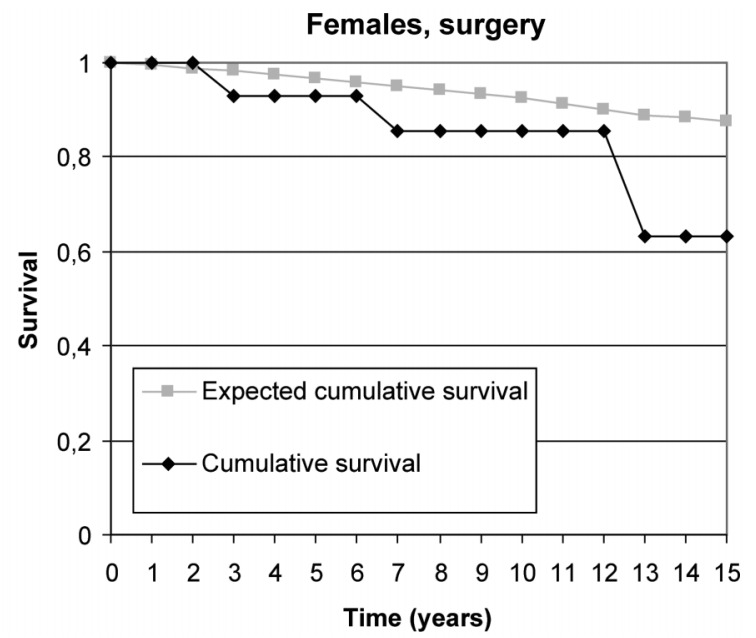

Figure 4 Cumulative observed and expected survival proportions in men and women after surgery. 
certificates are completed as instructed and can be coded according to rules of WHO and registered at Statistics Finland. The rest, the most inconsistently filled death certificates, $7 \%$ of all death certificates in 1995, are sent for validation to a panel representing both nosological and medical expertise. In 1995, $1.4 \%$ of all death certificates remained for reference back to the certifiers. Another important reason for high validity is that autopsy rates both in medicolegal, and in clinical deaths are at high levels in Finland. We found that a majority of deaths, 48\%, were caused by cerebrovascular diseases and one-third of deaths were aneurysm related, due to either $\mathrm{SAH}$ or giant aneurysm mass effect. Most deaths (70\%) were attributable to cerebrovascular and cardiovascular diseases, supporting the hypothesis that aneurysmal disease is part of a more generalised vascular disease. Mortality did not differ significantly between endovascular and surgical groups, supporting the opinion that unruptured aneurysms can be coiled or clipped. It is known that there are some differences between aneurysmal disease in Finnish and in other western countries (like higher incidence for rupture, differences in location), but outcome differences are not widely studied. Treatment and patient selection in Finland in 1990s were most likely same as in other countries because studies of these differences are from recent years.

We found, unexpectedly, that women had lower RSR than men. Male patients treated with endovascular coiling or surgical clipping had no statistically significant excess mortality compared with matched general population. However, women had 20\% excess mortality in the endovascular group and $28 \%$ excess mortality in the surgical group at 15 -year follow-up. It is known that the incidence of SAH is higher among women than among men, and women have more often multiple aneurysms. ${ }^{19}$ 23-26 However, outcome after SAH has not differed between genders, ${ }^{23}$ and thus the difference in long-term death rate is somewhat surprising. The reason for this is unclear. The study population was small and may lack precision. However, in recent studies, vascular physiology has been found to differ between genders, and cardiovascular risk increases with age more sharply in women than in men. ${ }^{27} 28$ Our finding confirms that there may be differences between female and male aneurysm patients, and further studies with larger population are needed.

\section{CONCLUSION}

Patients with untreated unruptured aneurysms have 50\% excess long-term mortality compared with general population. Men with treated unruptured aneurysms have a survival proportion comparable with matched general population. Women, instead, have $28 \%$ excess mortality after surgical treatment and $23 \%$ excess mortality after endovascular treatment of unruptured aneurysms.

Contributors LP designed the study, collected the data, analysed the data and drafted the manuscript; TL designed the study, analysed the data and edited the manuscript; LK-N designed the study, analysed the data and edited the manuscript; JÖ designed the study and edited the manuscript. All authors had full access to all of the data in the study and can take responsibility for the integrity of the data.

Funding This study was financially supported by the EVO funding of Pirkanmaa Hospital District and the Maire Taponen Foundation with grant number 21000.

\section{Competing interests None.}

Ethics approval Tampere University Hospital Ethics Committee and Statistics Finland.

Provenance and peer review Not commissioned; externally peer reviewed.

Open Access This is an Open Access article distributed in accordance with the Creative Commons Attribution Non Commercial (CC BY-NC 3.0) license, which permits others to distribute, remix, adapt, build upon this work non-commercially, and license their derivative works on different terms, provided the original work is properly cited and the use is non-commercial. See: http://creativecommons.org/licenses/by-nd/3.0/

\section{REFERENCES}

1 Pajunen $\mathrm{P}$, Paakkonen $\mathrm{R}$, Hamalainen $\mathrm{H}$, et al. Trends in fatal and nonfatal strokes among persons aged 35 to $>$ or $=85$ years during 1991-2002 in Finland. Stroke 2005; $36: 244-8$

2 Inagawa T. Trends in incidence and case fatality rates of aneurysmal subarachnoid hemorrhage in Izumo City, Japan, between 1980-1989 and 1990-1998. Stroke 2001;32:1499-507.

3 Pobereskin LH. Incidence and outcome of subarachnoid haemorrhage: a retrospective population based study. J Neurol Neurosurg Psychiatry 2001;70:340-3.

4 Dennis J, Nieuwkamp MD, Larissa $E$, et al. Changes in case fatality of aneurysmal subarachnoid haemorrhage over time, according to age, sex, and region: a meta-analysis. Lancet Neurol 2009:8:635-42.

5 Inagawa T. What are the actual incidence and mortality rates of subarachnoid hemorrhage? Surg Neurol 1997;47:47-52.

6 Broderick JP, Brott TG, Duldner JE, et al. Initial and recurrent bleeding are the major causes of death following subarachnoid hemorrhage. Stroke 1994;25:1342-7.

7 Sarti C, Tuomilehto J, Salomaa V, et al. Epidemiology of subarachnoid hemorrhage in Finland from 1983 to 1985. Stroke 1991:22:848-53.

8 Ingall TJ, Whisnant JP, Wiebers DO, et al. Has there been a decline in subarachnoid hemorrhage mortality? Stroke 1989;20:718-24.

9 Qureshi Al, Suri MF, Nasar A, et al. Trends in hospitalization and mortality for subarachnoid hemorrhage and unruptured aneurysms in the United States. Neurosurgery 2005;57:1-8.

10 Stegmayr B, Eriksson M, Asplund K. Declining mortality from subarachnoid hemorrhage: changes in incidence and case fatality from 1985 through 2000 Stroke 2004;35:2059-63.

11 Truelsen T, Bonita R, Duncan J, et al. Changes in subarachnoid hemorrhage mortality, incidence, and case fatality in New Zealand between 1981-1983 and 1991-1993. Stroke 1998:29:2298-303.

12 Olafsson E, Hauser WA, Gudmundsson G. A population-based study of prognosis of ruptured cerebral aneurysm: mortality and recurrence of subarachnoid hemorrhage. Neurology 1997;48:1191-5.

13 Huttunen $T$, von und Zu Fraunberg $M$, Koivisto $T$, et al. Long-term excess mortality of 244 familial and 1502 sporadic one-year survivors of aneurysmal subarachnoid hemorrhage compared with a matched Eastern Finnish catchment population. Neurosurgery 2011;68:20-7.

14 Molyneux AJ, Kerr RS, Birks J, et al. Risk of recurrent subarachnoid haemorrhage, death, or dependence and standardised mortality ratios after clipping or coiling of an intracranial aneurysm in the International Subarachnoid Aneurysm Trial (ISAT): long-term follow-up. Lancet Neurol 2009:8:427-33.

15 Ronkainen A, Niskanen M, Rinne J, et al. Evidence for excess long-term mortality after treated subarachnoid hemorrhage. Stroke 2001;32:2850-3.

16 Wiebers DO, Whisnant JP, Huston J 3rd, et al. International Study of Unruptured Intracranial Aneurysms, Investigators. Unruptured intracranial aneurysms: natural history, clinical outcome, and risks of surgical and endovascular treatment. Lancet 2003;362:103-10.

17 Ederer $\mathrm{F}$, Heise $\mathrm{H}$. Instructions to IBM 650 programmers in processing survival computations. Methodological note no. 10. Bethesda, MD: End Results Evaluation Section, National Cancer Institute, 1959.

18 Hakulinen T, Tenkanen L, Abeywickrama $\mathrm{K}$, et al. Testing equality of relative survival patterns based on aggregated data. Biometrics 1987:43:313-25.

19 Juvela S, Porras M, Poussa K. Natural history of unruptured intracranial aneurysms: probability and risk factors for aneurysm rupture. J Neurosurg 2008;108:1052-60.

20 Juvela S, Porras M, Heiskanen O. Natural history of unruptured intracranial aneurysms: a long-term follow-up study. J Neurosurg 1993;79:174-82.

21 Britz GW, Salem L, Newell DW, et al. Impact of surgical clipping on survival in unruptured and ruptured cerebral aneurysms: a population-based study. Stroke 2004;35:1399-403.

22 Lahti RA, Penttila A. The validity of death certificates: routine validation of death certification and its effects on mortality statistics. Forensic Sci Int 2001;115. $15-32$.

23 Kongable GL, Lanzino G, Germanson TP, et al. Gender-related differences in aneurysmal subarachnoid hemorrhage. J Neurosurg 1996;84:43-8.

24 Eden SV, Meurer WJ, Sanchez BN, et al. Gender and ethnic differences in subarachnoid hemorrhage. Neurology 2008;71:731-5.

25 Koffijberg H, Buskens E, Granath F, et al. Subarachnoid haemorrhage in Sweden 1987-2002: regional incidence and case fatality rates. J Neurol Neurosurg Psychiatry 2008;79:294-9.

26 de Rooij NK, Linn FH, van der Plas JA, et al. Incidence of subarachnoid haemorrhage: a systematic review with emphasis on region, age, gender and time trends. J Neurol Neurosurg Psychiatry 2007;78:1365-72.

27 Jousilahti P, Vartiainen E, Tuomilehto J, et al. Sex, age, cardiovascular risk factors, and coronary heart disease: a prospective follow-up study of 14786 middle-aged men and women in Finland. Circulation 1999:99:1165-72.

28 Mosca L, Manson JE, Sutherland SE, et al. Cardiovascular disease in women: a statement for healthcare professionals from the American Heart Association. Writing Group. Circulation 1997;96:2468-82. 